\title{
O OLHAR DOS AGRICULTORES FAMILIARES DO MUNICÍPIO DE ARAPONGA-MG SOBRE SUA ORGANIZAÇÃO SOCIAL E PRODUTIVA: UMA DISCUSSÃO PAUTADA NAS REPRESENTAÇÕES SOCIAIS
}

\author{
Edna Lopes Miranda ${ }^{1}$ \\ Ana Louise de Carvalho Fiúza ${ }^{2}$ \\ Sheila Maria Doula
}

\begin{abstract}
RESUMO
Este estudo teve por objetivo compreender as possibilidades de organização coletiva dos agricultores familiares a partir das práticas rotineiras de sociabilidade. Analisouse, de forma particular, o modo como os agricultores familiares da Zona da Mata Mineira desenvolviam as suas práticas coletivas de organização produtiva no cultivo do café. A pesquisa teve um caráter cross-sectional, com a realização pontual de doze (12) entrevistas aos agricultores familiares que moram na comunidade rural de São Joaquim, no munícipio de Araponga/MG. Os resultados mostraram que, na percepção dos agricultores, a organização produtiva tinha um significado de bem comum, de busca por melhorias das condições de vida e trabalho no campo que se baseia na "união", "ajuda mútua" e "solidariedade". Constatou-se claramente uma tendência cultural dos entrevistados a se reconhecerem enquanto "agricultores familiares" e também como participantes deste processo, já que suas representações sociais partem de um discurso no qual o pequeno agricultor é valorizado e reconhecido pela sua experiência. Por fim, as representações sociais dos agricultores sobre a sua organização produtiva têm também uma dimensão identitária construída a partir das relações estabelecidas com o território e com a cultura através dos valores, tradições, crenças e costumes.
\end{abstract}

Palavras-chave: análise de conteúdo, práticas cotidianas.

\section{THE LOOK OF FAMILY FARMERS IN ARAPONGA-MG COUNTY ON THEIR PRODUCTION ORGANIZATION: A DISCUSSION GUIDED IN SOCIAL REPRESENTATIONS}

\begin{abstract}
This study aimed to understand the possibilities of the familiar farmers collective organization from the routine sociabilitiy practices. It was analised, particularly, how the familiar farmers from Zona da Mata Mineira used to develop their collective

\footnotetext{
${ }^{1}$ Graduada em Economia Doméstica (UFV). Mestre em Economia Doméstica (UFV). Doutoranda em Extensão Rural (UFV). E-mail: edna.miranda04@hotmail.com

${ }^{2}$ Professora do Departamento de Economia Rural (UFV). Doutora em Ciências Sociais em Desenvolvimento, Agricultura e Sociedade (UFRRJ). E-mail: analouise@ufv.br

${ }^{3}$ Professora do Departamento de Economia Rural (UFV). Doutora em Antropologia Social (USP). E-mail: sheila@ufv.br.
} 
practices of productive organization in coffee cultivation. The research can be characterized as cross-sectional, relying on twelve (12) interviews to the familiar farmers that live in a rural community in São Joaquim, Araponga municipality/MG. The results showed that in the farmers perception the productive organization had a common meaning, of searching improvements in the life and work condition in the field based on the "union", "mutual help" and "solidarity". It was clearly found a cultural trendy by the interviewers to recognize themselves as "familiar farmers" and also as participants of this process, regarding that their social representations come from a discourse where the small farmer is valorized and recognized by thier experiences. Finally, the farmers social representations about their productive organization have also an identity construction from the setting relationships with the territory and with the culture through values, beliefs and custos.

Keywords: content analysis, routine practices.

\section{INTRODUÇÃO}

A forma como os costumes se constituíram em um instrumento de ação coletiva voltado para o enfrentamento das transformações socioeconômicas enfrentadas pelos camponeses já se constituiu em objeto de estudos brilhantes como os de Duby (1962), Thompson (1998) e Polanyi (2000), dentre outros clássicos da sociologia rural. Contudo, estudar as formas atuais pelas quais os agricultores familiares vêm constituindo as suas práticas, ora de resistência e enfrentamento, ora de adaptação ao aprofundamento das práticas e relações de produção capitalistas, se constitui em uma oportunidade de compreender melhor a forma como a agricultura familiar se mantém viva e reproduzindo as suas condições sociais de existência.

As discussões acerca da agricultura familiar tiveram maior enfoque no decorrer da década de 1990, com a emergência dos problemas relacionados à grande concentração fundiária, ao modelo de organização sociopolítico e econômico e o fortalecimento do movimento dos trabalhadores que lutavam pelo direito à terra. Neste sentido, muitos estudos vêm sendo produzidos visando aprofundar o conhecimento acerca da produção familiar na agricultura, especialmente no que se refere às formas que este segmento vem desenvolvendo no sistema capitalista de produção contemporâneo, bem como seu processo de adaptação e resistência ao sistema de mercado diante da intensificação das relações capitalistas. A agricultura familiar caracteriza-se pela sua relação entre trabalho e gestão familiar, com ênfase para a diversificação produtiva e para a sustentabilidade dos sistemas de produção tradicionais, destacando a autonomia relativa do pequeno produtori. Além disso, se considerarmos o Brasil como um país onde persistem até os dias atuais raízes agrárias centradas no latifúndio, no qual as políticas públicas são voltadas em sua grande maioria para o agronegócio, podemos dizer que a agricultura familiar subsiste pressionada pelo agronegócio - como apontam os estudos sobre a questão agrária brasileira (TEDESCO, 1999; SCHNEIDER, 2006; WANDERLEY, 2001). Esta situação não é diferente na região da Zona da Mata Mineira, mais especificamente no município de Araponga/MG, no qual os pequenos agricultores vêm desenvolvendo estratégias de resistência e adaptação com o intuito de melhorar as condições de trabalho e vida no campo.

Tendo em vista as idéias esboçadas acima, cabe-nos questionar: quais são as representações sociais dos pequenos agricultores sobre sua organização social e produtiva no cultivo do café? Quais são suas estratégias de mobilização? Sendo 
assim, para entender a organização social e produtiva familiar, é necessário considerar as ações e estratégias dos pequenos agricultores no espaço rural.

Neste trabalho, a categoria "agricultura familiar" é usada de forma geral para designar unidades produtivas nas quais a terra, os meios de produção e o trabalho estão estritamente ligados ao grupo familiar. De acordo com Wanderley (2001), as unidades de produção familiares têm como características principais uma organização produtiva fundamentada no trabalho familiar e processos particulares de sucessão hereditária, uma vez que a terra, para esses agricultores, não é só um meio de produção, nem unicamente seu maior patrimônio, mas é parte do seu modo de vida. Segundo Corrêa e Gerardi (2002), o pequeno agricultor familiar atual possui características que o diferenciam do camponês devido à abertura do mundo rural ao modo de vida moderno que possibilitou esta interconexão entre o rural e o urbano. Desta forma, o agricultor familiar está integrado ao mercado de diversas maneiras e, portanto, sofre os efeitos diretos e indiretos da reprodução do capital.

A partir dessas premissas, o presente artigo pretendeu analisar como os pequenos agricultores do munícipio de Araponga/MG, em particular da comunidade de São Joaquim, têm percebido a sua organização social e produtiva, enfatizando as atribuições simbólicas relacionadas às estratégias desenvolvidas em sua vida cotidiana. Assim, os resultados desta pesquisa referem-se unicamente a estes casos e não a um contexto geral dos pequenos agricultores. Apresenta-se, inicialmente, uma discussão sobre as teorias de Representações Sociais para entender a organização social e produtiva dos pequenos agricultores da comunidade de São Joaquim no Município de Araponga/MG, bem como as suas práticas cotidianas desenvolvidas no cultivo do café em suas propriedades rurais. Em seguida, apresentam-se os dados empíricos da pesquisa.

\section{CONCEPÇÃO TEÓRICA DAS REPRESENTAÇÕES SOCIAIS}

Na obra que fundou a Sociologia moderna de Èmile Durkheim (1975) é que se encontram as primeiras alusões ao conceito de Representações Sociais. Para este autor, a ideia de representação social parte do conceito de representações coletivas, entendidas como formas de pensamento que a sociedade elabora para expressar sua realidade e que são incorporadas e interiorizadas pelos indivíduos através das normas e regras que constituem a estrutura social. Assim, são formados os sistemas de representação coletivos nos quais é possível criar esquemas de percepção, juízos que fundamentam as maneiras sociais de agir, pensar e sentir dos indivíduos.

Dentre as bases teóricas adotadas neste estudo estão os questionamentos acerca das representações sociais e sua influência sobre as percepções e significados que os atores sociais ${ }^{4}$ exprimem a respeito de suas ações na organização social e produtiva da agricultura familiar. Por isso, falar em representações sociais implica em considerá-las como emergentes na dimensão simbólica da vida social, pois servem para agir sobre o mundo e sobre os outros.

Segundo Jodelet $(2001$, p. 8), a representação social é "uma forma de conhecimento socialmente elaborada e compartilhada, que tem um objetivo prático e concorre para a construção de uma realidade comum a um conjunto social". Partindo desta concepção, as representações são criadas para informar o homem sobre o mundo à sua volta, construir o conhecimento sobre como se comportar, dominá-lo

\footnotetext{
${ }^{4}$ Apreendidos como "sujeitos ativos" na construção dos processos sociais em que estão envolvidos, segundo a perspectiva de análise centrada nos atores, de Long e Van der Ploeg (2011).
} 
físico e intelectualmente, identificar e resolver os problemas que se apresentam. Esta premissa pode ser observada nos resultados da pesquisa realizada por Nino e Sacco dos Anjos (2015) no munícipio de Pelotas/RS, ao analisarem as representações sociais dos produtores sobre a propriedade da terra e uso dos recursos naturais considerando as disposições da legislação ambiental.

Seguindo esta mesma perspectiva, Quintero (2008) enfatiza que as representações sociais manifestam-se na linguagem e nas práticas, como consequência da sua função simbólica que podem ser utilizadas para codificar e classificar o mundo da vida. Sendo assim, não basta apenas que um fenômeno seja falado por um grupo de pessoas para que se torne objeto de investigação no campo das representações sociais, mas que este tenha relevância e implicação na vida cotidiana do grupo, fazendo com que as pessoas se posicionem, não somente de forma abstrata, mas também quanto às práticas sociais desenvolvidas no dia a dia do grupo.

De acordo com Goffman (1999), a vida cotidiana pode ser comparada a um teatro em que os indivíduos desempenham papéis diferentes e interagem com outros indivíduos através dos seus comportamentos físicos e verbais. Desta forma, o cotidiano das ações dos atores tem variados palcos que correspondem aos espaços da materialidade da cultura e suas representações. Todavia, neste estudo, as formas como os pequenos agricultores se mobilizam precisa ser compartilhada entre os vários atores sociais para que se torne um ponto de negociação, de práticas e de identidades.

A partir destas colocações e tomando como referência a geografia do cotidiano de Goffman (1999), verifica-se a íntima relação entre práticas e representações sociais, já que algumas práticas permitem descobrir aspectos da representação que não são verbalizados, mas que podem ser testemunhados por meio de atitudes e práticas cotidianas. Ancoradas nestes autores, as representações sociais sobre a organização social e produtiva dos agricultores familiares adquirem grande importância, uma vez que indicam o conhecimento pelo qual os indivíduos dão significados acerca do que vivem, nas relações que estabelecem, nos objetos que utilizam, entre outros elementos que caracterizam a representação de um indivíduo ou do grupo no qual está inserido.

Partindo da ideia de que as representações sociais conferem um sentido a determinadas ações e atitudes das pessoas, esta é tratada neste estudo como uma categoria interpretativa das práticas cotidianas desenvolvidos pelos pequenos agricultores, na medida em que se apresenta como uma modalidade de conhecimento construída e compartilhada no ambiente social. Além disso, dada a sua capacidade operacional, as representações sociais podem proporcionar um maior entendimento sobre as práticas desenvolvidas pelos pequenos agricultores em sua organização social e produtiva do café, bem como nos levam a questionar se os agricultores familiares seriam conformados com o modelo capitalista de produção, ou ao contrário, lançam mão de estratégias de resistência a este modelo, permitindo a criação de espaços de autonomia. 


\section{AS PRÁTICAS COTIDIANAS DOS PEQUENOS AGRICULTORES EM SUA ORGANIZAÇÃO SOCIAL E PRODUTIVA}

A organização social e produtiva dos agricultores familiares surge como produto da união dos esforços individuais na perspectiva de encontrar, de maneira conjunta, a solução para os problemas detectados em seu cotidiano do trabalho. Neste sentido, a organização social dos agricultores, muitas vezes, é o resultado da ausência do Estado na solução dos problemas enfrentados por estes, especialmente no que se refere às necessidades básicas (habitação, serviços públicos, educação e saúde). Por isso, quanto mais agudos são os problemas ou mais desafiantes os propósitos comuns, mais esforços são despendidos para alcançar maiores níveis de organização. Portanto, pode-se dizer que se a sociedade não contar com redes de organização, é muito difícil amadurecer processos democráticos (GONZALEZ, 1995).

Autores como Schneider (2006), Scott (2002) e Silva (1998) destacam a importância em se analisar as práticas, processos e formas de organização que são adotadas por agricultores de base familiar para construir alternativas viáveis e sustentáveis de subsistência, sendo capazes de agir e decidir sobre sua própria vida em uma situação de dominação econômica, política e cultural. Na obra Weapons Of The Weak: Everyday Forms of Peasant Resistance, o antropólogo americano James Scott (1985), enfatiza as estratégias de resistência utilizadas pelos camponeses da Malásia em virtude da tecnificação na produção de arroz e aponta as relações de poder entre os indivíduos subordinados que, muitas vezes, são obrigados a adotar uma postura estratégica na presença de quem os domina. No entanto, a adoção desta postura não implica necessariamente em um confronto direto, mas em desenvolver estratégias silenciosas e discursos ocultos entre seus pares em relação à dominação que lhes é imposta. Nem sempre a resistência tem o objetivo de eliminar as relações de dominação ou de desestruturar o sistema, mas tem a intenção de sobreviver dentro dele.

Assim, os estudos desenvolvidos por Scott $(1985,2002)$ propõem compreender as relações de dominação a partir das interações sociais cotidianas, demonstrando uma afinidade com o pensamento de Goffman (1999), que se dirige para os contatos face a face, cuja tese central carrega implicitamente a ideia de que as pessoas, por intermédio de suas interações, teatralizam as relações experimentadas no cotidiano. No entanto, vale ressaltar que a epistemologia defendida por Scott (1985) não se caracteriza apenas pelo interacionismo simbólico, mas entende que as formas de representação que os indivíduos utilizam nas relações cotidianas com seus pares e com seus opositores são também definidas pela estrutura social.

Neste sentido, Scott (1985) argumenta que os indivíduos com menor poder, seja econômico ou político, direcionam suas ações de modo a utilizar sua capacidade criativa para reorganizar relações e garantir a sua organização social e produtiva. Este aspecto pode ser observado também em pesquisa realizada por Silva (1998) com os camponeses nortenhos, nomeadamente minhotos, ao afirmar que as práticas dos agricultores sejam de confrontação, sejam de conformismo e adaptação à ordem vigente, guardam estreita correspondência com as suas demandas da vida cotidiana, com o seu estilo de vida e com o processo de constituição de suas identidades coletivas e individuais. Portanto, ambos os autores concordam que o repertório de ação coletiva implica em estratégias de resistência e adaptações por parte dos agricultores ao contexto que lhes é colocado. 
Corroborando esta mesma perspectiva, o artigo Resistência e empoderamento no meio rural, de Ferreira et al. (2007), retrata as diferentes formas de resistência e luta dos agricultores paranaenses em busca da afirmação do caráter multidimensional da pequena agricultura familiar e a reafirmação de sua identidade como agricultores que passam a ser atores nos processos de desenvolvimento sustentável. Neste sentido, Rambaud (1969) acrescenta que os trabalhadores da terra são capazes de desenvolver iniciativas em continuidade com seus pertencimentos antigos e em luta contra as formas de dominação política ou econômica vigente, uma vez que "a terra trabalhada por uma família não é apenas um espaço técnico, mas, também, o espaço da liberdade individual conquistada sobre a sociedade e, mais ainda, contra o Estado" (p. 111).

\section{PROCEDIMENTOS METODOLÓGICOS}

Para alcançar o objetivo proposto, recorreu-se à pesquisa qualitativa, na qual a coleta e análise das informações não são estanques e mantêm-se em relações recíprocas com a teoria. Na concepção de Minayo (2004), a pesquisa qualitativa envolve metodologias capazes de incorporar a questão do significado e da intencionalidade como inerentes aos atos, às relações e às estruturas sociais, sendo essas últimas tomadas tanto no seu advento quanto na sua transformação, como construções humanas significativas. Desta forma, a categoria de pesquisa selecionada foi o estudo de caso, pois somente o estudo intensivo de um caso permite a descoberta de determinadas relações (TRIVIÑOS, 1995).

Para proceder à coleta de dados foi realizada, em um primeiro momento, uma pesquisa bibliográfica acerca da forma de organização produtiva dos pequenos agricultores, com o intuito de fundamentar teoricamente o objeto de estudo. Segundo Lima e Mioto (2007), a pesquisa bibliográfica vai além da simples observação de dados contidos nas fontes pesquisadas, pois imprime sobre eles a teoria, a compreensão crítica do significado neles existente, que significa realizar um movimento incansável de apreensão dos objetivos, de observância das etapas, de leitura, de questionamentos e de interlocução crítica com o material bibliográfico.

Já em um segundo momento, a pesquisa teve um caráter cross-sectional, com a realização pontual de entrevistas voltadas para compreender o fenômeno da organização produtiva coletiva culturalmente sustentada. Para a escolha dos entrevistados, adotou-se como parâmetro a amostra não-probabilística, em que os sujeitos participantes foram selecionados pelo critério de intencionalidade após reuniões com os próprios agricultores.

O universo empírico e lócus da pesquisa escolhido foi o município de Araponga/MG, mais precisamente a comunidade de São Joaquim, onde a agricultura predominante praticada pelo pequeno agricultor é, por definição, uma agricultura familiar de subsistência em áreas menores que 100 hectares. Uma das principais características desta comunidade é o fato de que ali vivem pequenos agricultores que foram fundadores das principais organizações de trabalhadores rurais e agricultores familiares do município, como o Sindicato de Trabalhadores Rurais (STR), a Associação dos Agricultores Familiares de Araponga (AFA) e a Cooperativa de Crédito da Agricultura Familiar e Economia Solidária (Ecosol). Desta forma, o que nos levou a escolher o caso de Araponga foi a constatação de que nesse pequeno município no interior de Minas Gerais, com população predominante rural, essas dinâmicas de ação coletiva levaram a uma complexificação do tecido associativo local para além das fronteiras municipais.

Localizado na Zona da Mata de Minas Gerais, como mostra o mapa a seguir, este município possui uma população de aproximadamente 8.328 habitantes, 
dos quais cerca de $70 \%$ vivem no meio rural, sendo $90 \%$ das propriedades de base familiar (IBGE, 2010).

Figura 1 - Localização do munícipio de Araponga na mesorregião da Zona da Mata Mineira

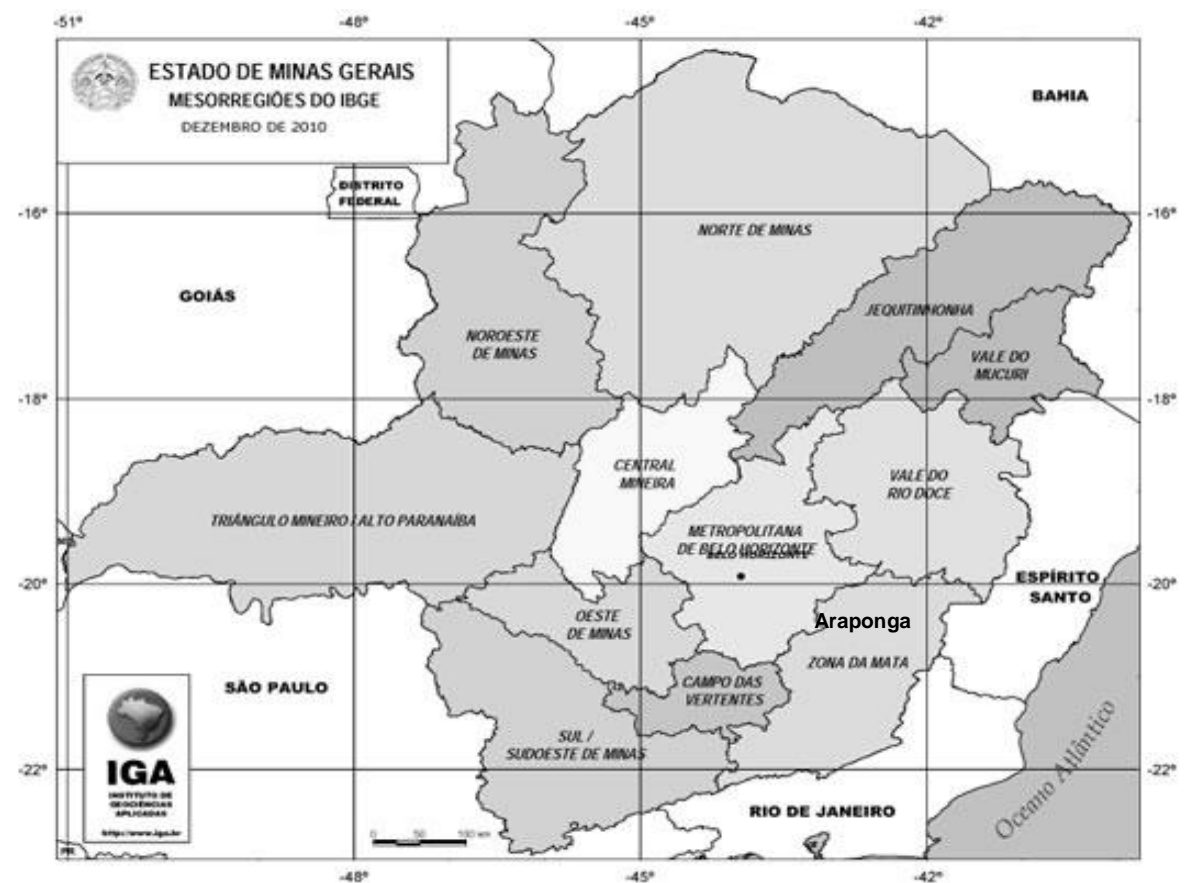

Fonte: Instituto de Geociências Aplicadas (2012).

A renda advinda do café se constitui na base da economia do município, seguindo-se da pecuária e do turismo rural desenvolvido nas propriedades em torno do Parque Estadual da Serra do Brigadeiro. Ocupado, em sua maioria, por pequenos agricultores, este município apresenta uma estrutura agrária que se caracteriza por uma elevada fragmentação da propriedade rural, cuja viabilidade depende da tenacidade dos agricultores e da adoção de estratégias e formas de resistência cotidianas (CTA, 2002).

Tendo em vista a realização de uma pesquisa qualitativa que tem como enfoque a Teoria das Representações Sociais, a amostra foi delimitada em doze entrevistas individuais junto aos pequenos agricultores. Nas entrevistas, procurou-se traçar as ações e estratégias dos agricultores, bem como a relação com a terra no cultivo do café e a percepção dos mesmos sobre as formas de mobilização e organização social produtiva. Neste sentido, o roteiro de entrevista foi elaborado com base em três elementos apresentados na Teoria das Representações Sociais por Jodelet (2001) e que sustentam a pesquisa: o sujeito, a representação e o objeto - quem sabe e de onde sabe? O que sabe e como sabe? Sobre o que sabe e com qual efeito?

Para a obtenção dos dados referentes à caracterização e perfil dos pequenos agricultores foram analisadas as seguintes variáveis: idade, sexo, estado 
civil, escolaridade e vínculo com a agricultura. Na caracterização da organização produtiva dos agricultores foram identificadas as práticas de cultivo da propriedade e suas formas de participação na organização, no sentido de buscar compreender as representações sociais dos agricultores em relação a sua organização produtiva, bem como o desenvolvimento da mesma na região. Para tanto, as entrevistas foram divididas em duas partes: a primeira, constituída de itens referentes ao perfil sociodemográfico dos participantes; e a segunda, composta por questões norteadoras: O que é organização social e produtiva dos agricultores? O que ela representa para você? Quais são os pontos fortes e fracos da organização?

A pesquisa de campo foi realizada entre setembro e outubro de 2015 no município de Araponga/MG. Neste período, foram realizadas três visitas as propriedades rurais onde foram feitas dez entrevistas e uma visita no final de semana para participar de uma reunião do Sindicato Rural dos Trabalhadores, na qual realizamos duas entrevistas. Após as entrevistas, o próximo passo foi a transcrição e a análise das mesmas, com o olhar atento às visões de mundo dos atores sobre os aspectos discutidos anteriormente.

Nessa abordagem, utilizaram-se as representações sociais como instrumento de interpretação e também como suporte metodológico para categorizar o que foi apreendido nas falas dos entrevistados, permitindo-nos classificar e compreender as múltiplas visões de mundo dos pequenos agricultores. Entendendo que são vários os modos de imaginar e representar o espaço de vida e de trabalho dos agricultores familiares, elaboramos, a partir da análise dos dados qualitativos, uma cartografia crítica do cotidiano, no sentido de identificar as formas ou modalidades de resistência que operam no processo de organização produtiva e social desses agricultores. Ancorada na teoria jodeliana de representações sociais e entendendo que a cartografia é também uma representação social deste espaço singular, optamos por denominá-la de "cartografia da resistência".

Procurando ser coerente com a proposta da pesquisa, para análise dos dados recorreu-se à teoria das representações sociais como abordagem e a técnica de análise de conteúdo proposta por Bardin (1994), para discussão das informações qualitativas apresentadas pelas entrevistas. A análise do conteúdo das entrevistas buscou desvendar, fundamentalmente, não só as representações sociais dos pequenos agricultores da comunidade de São Joaquim sobre sua organização produtiva do café, bem como indagar acerca das suas práticas e percepções sobre a propriedade e uso da terra. De modo geral, as representações sociais ou coletivas devem ser entendidas como processos ou fenômenos mentais compartilhados, através dos quais as pessoas organizam suas vidas.

Desta forma, a análise do conteúdo das entrevistas buscou definir como os pequenos agricultores da comunidade de São Joaquim em Araponga/MG se organizam, quais os pontos fracos e fortes desta organização, bem como entender suas práticas e percepções sobre suas práticas cotidianas de trabalho. Para tanto, os dados colhidos foram transcritos, ordenados, classificados e articulados ao referencial teórico da pesquisa, buscando responder à questão investigada. 


\section{RESULTADOS E DISCUSSÕES}

Com o suporte da teoria da representação social de Jodelet (2001) vimos na prática como os agricultores atribuem significados a sua trajetória de vida, a sua relação com a terra, com o cotidiano rural e também com o ambiente produtivo, que juntos fazem parte de um conjunto de informações que nos permite observar qual a representação que os agricultores têm de si, explicar os comportamentos dos grupos sociais e entender como o processo de organização social e produtiva dos agricultores dentro de um contexto de agricultura familiar acontece. Além disso, para melhor captar as percepções da realidade investigada, considerou-se a análise de conteúdo dos depoimentos dos produtores rurais, dada a importância das falas que revelam, mesmo na simplicidade do vocabulário, o verdadeiro significado deste estudo. Desta forma, optou-se por formar dois conjuntos de informações que emergiram do processo de coleta de dados, resultando na seguinte estrutura de análise:

$1^{a}$ ) Perfil dos produtores rurais - este primeiro conjunto está relacionado ao perfil socioeconômico e cultural dos produtores. Desta forma, a intenção foi identificar traços comuns aos produtores em seu trabalho e nas relações com a comunidade a que pertencem.

$2^{\mathrm{a}}$ ) Experiência da organização produtiva - diz respeito às questões relacionadas às representações sociais dos pequenos agricultores, que, aliadas ao cotidiano rural, constroem suas percepções sobre a realidade da organização produtiva do café. Neste âmbito, o agricultor reflete e avalia sua participação nas decisões dentro da organização e cria estratégias para sobreviver dentro dela. Portanto, as categorias selecionadas foram construídas no âmbito da própria pesquisa e surgiram da convergência de dados obtidos na prática investigada.

\subsection{CARACTERIZAÇÃO E PERFIL DOS AGRICULTORES}

Com respeito ao sexo e faixa etária dos agricultores, constatou-se que dos doze entrevistados, todos eram do sexo masculino, encontrando-se seis na faixa entre 29 e 39 anos, quatro na faixa entre 40 e 59 anos e dois acima de 60 anos. Percebeu-se, então, assim como no cenário nacional, uma tendência à permanência das pessoas mais velhas nas propriedades rurais, o que tende a influenciar no processo de organização produtiva, sendo intensificado com a evasão dos jovens para a cidade, principalmente em busca de estudos. No que se refere ao estado civil dos produtores, dois eram solteiros; nove casados e um viúvo. Quanto à escolaridade, constatou-se que todos os agricultores entrevistados estudaram até a $4^{a}$ série do ensino fundamental.

Em relação à posse da propriedade rural, a totalidade dos agricultores entrevistados eram proprietários da terra, com área média 10 ha. Sendo assim, os agricultores tinham, em média, a posse da terra há 30 anos, tendo sido obtidas por meio de herança ou compra do terreno. Além do café, eles plantavam, principalmente, milho e feijão, além de se dedicarem à bovinocultura. Neste contexto, trata-se de agricultores com uma pequena unidade produtiva, com baixo grau de mecanização e que utiliza de forma exclusiva a mão de obra familiar. 


\subsection{AS REPRESENTAÇÕES SOCIAIS DOS AGRICULTORES SOBRE A ORGANIZAÇÃO PRODUTIVA DO CAFÉ}

As representações sociais sobre a organização social e produtiva do café foram analisadas com base no material coletado pelas entrevistas e ponderadas pela análise temática de conteúdo. No que se refere às "Concepções da organização produtiva", para oito entrevistados a organização produtiva passa a ideia de mobilização/coletividade e já para quatro entrevistados a organização dá ideia de união, solidariedade e ajuda. Quando perguntados o que seria uma organização produtiva, os agricultores destacaram de forma majoritária, como uma "mobilização coletiva" em prol dos interesses do grupo, como observado na fala de um dos entrevistados: "Uma mobilização coletiva de um grupo em busca de melhorias nas condições de vida e trabalho no campo" (Entrevistado 05, 53 anos, agricultor).

Na percepção dos entrevistados, a organização social e produtiva também se baseia na relação de ajuda mútua entre eles, união e confiança, o que demonstra um alto nível de organização por parte dos agricultores. Desta forma, a evidência de que as organizações buscam respostas coletivas e solidárias diante dos constrangimentos vividos pelos agricultores familiares corrobora com a visão de Gonzalez (1995) ao afirmar que quanto mais críticos são os problemas, mais urgente a necessidade de se organizar.

Os dados resultantes das entrevistas mostraram que, ao serem questionados por que são agricultores, algumas categorias estiveram presentes na maioria das respostas dos entrevistados: por motivo de herança; porque nasceu na terra; por vocação; porque o pai era produtor rural e por tradição - como é possível observar nas falas a seguir:

Não tive oportunidade de estudar, porque tinha que trabalhar na roça, fiquei com a propriedade como herança, casei, construí minha família, tudo porque gosto da agricultura (Entrevistado 12, 53 anos, agricultor).

Meu pai sempre foi produtor rural, quando terminei os estudos, voltei para a propriedade para cuidar da terra, porque eles morreram (Entrevistado 02, 38 anos, agricultor).

Nota-se nas falas dos entrevistados que a falta de oportunidades sociais principalmente no que concerne à escassez de capital humano - foi um dos fatores determinantes para "ser" agricultor. Apesar disso, sete dos doze entrevistados declararam-se satisfeitos com uso que eles fazem da terra, que possui um significado que vai além do produtivo, como destaca um dos entrevistados: "É uma fonte de renda e lugar pra gente morar, gosto do meio rural, aqui ainda é o melhor lugar para viver com a família" (Entrevistado 08, 45 anos, agricultor).

Observou-se nos depoimentos que os agricultores familiares desejam ter uma atividade agrícola rentável e valorizada pela sociedade e pelas políticas públicas ao expressarem o "afeto à terra", o "gostar de trabalhar", ao sentirem-se orgulhosos com uma "roça bem cuidada", de sentirem-se "livres" por não terem um patrão, realizando o valor de ser "dono de si mesmo" e de "viver ao ar livre", "em contato com a natureza".

A partir desses questionamentos, podemos constatar que a organização produtiva do café para os pequenos agricultores, bem como a prática da agricultura, confunde-se com o próprio pertencimento à localidade, ao gosto pela terra e pela 
tradição e se destaca como uma condição para manter um modo de vida que seria impensável em outros espaços, principalmente na cidade. Constatou-se entre os agricultores uma espécie de significado simbólico da terra, ao ponto de afirmarem que não se desfariam dela em troca de outra atividade.

No entanto, mesmo sendo esta uma concepção majoritária entre os agricultores, vale ressaltar que o significado material e real do patrimônio também permeia as relações na produção familiar. Neste contexto, a identidade dos agricultores familiares é constituída a partir de tradições, saberes, crenças, comportamentos e valores, que consideram tanto as dimensões materiais quanto simbólicas.

Observa-se que a agricultura familiar é marcada pelas tradições, por hábitos e costumes que se perpetuam, por uma relação de pertencimento com a terra e com o território, o que vem fortalecer o pensamento de Candau (2011) de que não existe identidade sem memória, assim como não há memória sem identidade. Desta forma, as representações sociais dos agricultores sobre a sua organização produtiva têm também uma dimensão identitária que são essenciais para o enraizamento do indivíduo no grupo de pertencimento.

Diante do exposto, constatou-se que as representações sociais dos agricultores foram adquiridas através da memória coletiva, ou seja, pelas práticas sociais vivenciadas pelo grupo em seu cotidiano. Esta cartografia subjetiva do cotidiano rural da organização produtiva dos agricultores nos trouxe uma representação crítica da realidade, evidenciando como estes atores sociais se organizam em seu espaço cotidiano, seja pela resistência e/ou adaptação ao modo capitalista de produção, como mostra a figura 2.

Figura 2 - Cartografia subjetiva do cotidiano rural da organização produtiva dos agricultores da comunidade de São Joaquim - Araponga/MG.
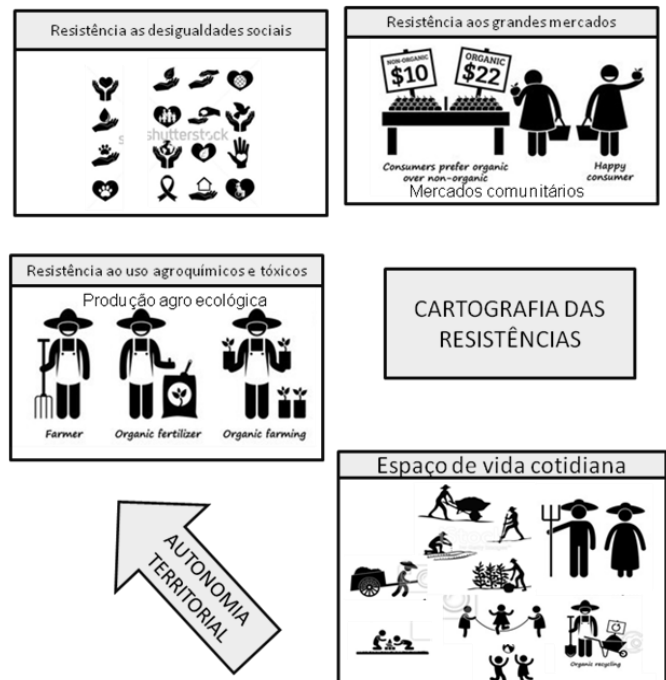

Fonte: Dados da pesquisa (2015).
CARTOGRAFIA DAS RESISTÊNCIAS

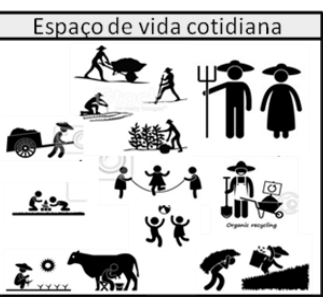

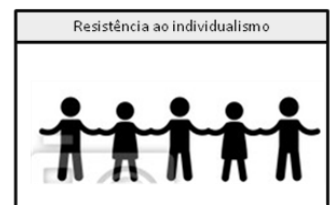

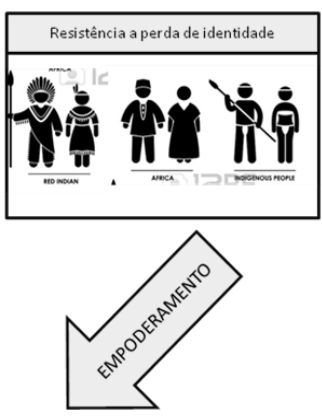

(1)


Partindo desta análise cartográfica, pode-se observar que os agricultores familiares da comunidade de São Joaquim têm em comum o fato de privilegiarem as ações não violentas, mas que levam a enfrentamentos, como por exemplo, resistência ao uso dos agrotóxicos, resistência aos grandes mercados, ao individualismo mercadológico próprio do capitalismo e, principalmente, uma resistência à perda da identidade e de um "modo de vida" das pessoas que moram no meio rural, como evidenciado nos relatos:

Na nossa feirinha, você pode encontrar alimentos fresquinhos, direto do produtor, um alimento de qualidade e diferenciado, coisa que você não vai encontrar em nenhum supermercado (Entrevistado 11, 40 anos, agricultor).

Aqui você pode ver que usamos somente insumos orgânicos que é daqui mesmo, como o esterco de boi e a palha do café. Não tem nada de veneno, quer dizer, agrotóxico em nossas plantações (Entrevistado 09, 42 anos, agricultor).

Desta forma, as representações sociais dos agricultores partem de um discurso no qual o agricultor familiar é valorizado e reconhecido pela sua experiência. Embora o cotidiano dos agricultores em sua organização produtiva seja também marcado por assimetrias e conflitos, eles evidenciam a possibilidade de criar coletivamente espaços de relações simétricas, através das práticas e atividades costumeiras desenvolvidas nas comunidades rurais.

Estes espaços estão presentes nos círculos de cooperação e solidariedade, nos dias de campo, nas reuniões da Cooperativa de Crédito da Agricultura Familiar (Ecosol), nas manifestações culturais (festas religiosas, quadrilhas e festa da colheita) e na vida cotidiana dos agricultores. Este cotidiano, por sua vez, deve ser entendido como um espaço singular em que se dão as vivências pessoais, os diferentes tipos de trocas e as mais variadas formas de resistência, que se balizam por uma autonomia territorial.

De posse dos resultados, esta cartografia subjetiva do cotidiano mostrou que as estratégias dos pequenos agricultores se situam entre um repertório cotidianamente construído que se caracteriza por práticas rotineiras, cujo repertório de ação não se dá somente pelo acesso à terra, mas também em prol da implementação de práticas relativas ao seu uso, o que confere à sua luta uma nova orientação cultural. Diante deste contexto, a cartografia de atuação dos agricultores sinalizou novas formas de produção e organização social da vida e do trabalho, nas quais se valoriza a autonomia do agricultor.

Pode-se perceber que, para os entrevistados, o campo, longe de ser um espaço homogêneo e pacífico, está entranhado de diferentes conflitos sociais, nos quais a terra deixou de ser percebida como um meio para a produção agrícola e ganhou notoriedade como uma componente importante de reprodução de um modo de vida particular. Ao serem questionados sobre os pontos fracos e fortes da organização, os depoimentos foram agrupados, considerando-se os significados das palavras-chave presentes nas falas dos agricultores (Quadro 1). 
Quadro 1- Pontos fracos versus pontos fortes da organização produtiva dos agricultores familiares da comunidade de São Joaquim, Araponga/MG

\begin{tabular}{|l|l|}
\hline Pontos fracos da organização & Pontos fortes da organização \\
\hline Falta de Mão de Obra & União do grupo \\
\hline Preço dos Insumos & Aumento da produtividade \\
\hline Evasão dos Jovens & Terra fértil, tranquilidade \\
\hline Estradas Ruins & $\begin{array}{l}\text { Troca de experiência e interação entre os } \\
\text { agricultores }\end{array}$ \\
\hline
\end{tabular}

Fonte: Dados da pesquisa, 2015.

A percepção dos agricultores sobre sua organização produtiva contém uma ambiguidade que expressa a contradição entre o modo de vida rural e as condições de trabalho na agricultura. Se de um lado os agricultores reconhecem a falta de mão de obra e o alto preço dos insumos (entre outros fatores), por outro, a vida no campo oferece vantagens sobre a vida na cidade, como tranquilidade, segurança, além de melhores condições de alimentação.

Esses fatores contribuem para uma imagem positiva do meio rural, expressa pela qualidade de vida oferecida às pessoas. Partindo deste contexto, na organização social e produtiva dos agricultores da comunidade de São Joaquim prevalece a economia das trocas, sendo intercambiados bens materiais, como dinheiro, mantimentos, ferramentas, entre outros, mas também elementos imateriais, como informações, afeto e solidariedade. Além disso, todas essas trocas também envolvem dimensões marcadamente simbólicas, como reconhecimento e prestígio.

Estes resultados evidenciam que na organização produtiva dos agricultores as relações sociais, as práticas de reciprocidade e as redes sociais de cooperação são utilizadas como recurso para formas de trabalho e produção e assim assumem uma característica de resistência por parte dos produtores. As relações de proximidade, as trocas e atividades em conjunto entre as famílias, o interconhecimento relativo às amizades e aos vizinhos são elementos aglutinadores da vida social local destes agricultores e, por isso, são fundamentais para a reprodução da agricultura familiar. Partindo desta perspectiva, é de se esperar que os atores sociais passem a ressignificar as suas relações sociais e adequá-las ao contexto que Ihes é oferecido, se adaptando diante de uma situação de constrangimento ou dominação provocada pelo sistema capitalista de produção.

Sendo assim, as práticas, atitudes e representações dos produtores rurais sobre sua organização social e produtiva conjugam princípios usualmente nomeados de "tradicionais", tais como o reforço dos laços de reciprocidade e proximidade nas comunidades rurais com relações tipicamente capitalistas nos mercados de trabalho e de produtos. Apesar do evidente fenômeno da mercantilização das práticas econômicas no campo, notou-se que os pequenos agricultores do munícipio de Araponga/MG têm realizado estratégias de resistência e também de reprodução social fundamentadas em relações de ajuda mútua, trocas de dias de trabalho e mutirão, oferecendo um horizonte profícuo acerca de como as lógicas mercantis podem ser contrapostas através de práticas cotidianas e das relações de proximidade entre as pessoas. Este aspecto também é apontado nos estudos de Schneider (2006), Scott (2002) e Silva (1998) ao enfatizarem a necessidade de se considerar as manifestações e práticas sociais não necessariamente hegemonizadas pelos agricultores em seu dia a dia.

Outra questão importante a ser destacada é que os dados resultantes das entrevistas mostraram que não há uma forma de pensar a realidade rural e também de produção, sobretudo no que se refere à organização social e produtiva dos 
pequenos agricultores fora do seu ambiente institucional, já que a maioria dos agricultores fazem parte da Cooperativa de Crédito da Agricultura Familiar e Economia Solidária (Ecosol) de Araponga. Esta cooperativa desponta como uma experiência de sucesso do ponto de vista da ação coletiva dos pequenos agricultores neste município. O discurso reproduzido pelos entrevistados sobre cooperação deriva em parte de uma representação positiva sobre a organização produtiva que está diretamente ligada à trajetória e participação do grupo na criação da cooperativa. Desta forma, suas falas apontam para um discurso que se assenta na "união", "ajuda" e "solidariedade", o que mostra claramente uma tendência cultural dos entrevistados como participantes do processo de organização produtiva.

Tendo em vista que as cooperativas surgiram no Estado de Minas Gerais no fim de 2004 e início de 2005, a Ecosol/Araponga é uma organização recente, mas que conta com uma forte mobilização por parte dos agricultores familiares e alto grau de organização produtiva, não somente do ponto de vista econômico, mas também com caráter identitário e de reconhecimento social por parte daqueles que trabalham na agricultura familiar, como pode ser percebido nestas falas:

Para mim, uma organização não tem dono, ela é de todos e por isto é dever de cada um participar e cuidar dela. O que faz dar certo são as pessoas. Aqui um respeita o outro, deixando todo mundo dar sua opinião (Entrevistado 03, 45 anos, agricultor).

Aqui nós somos unidos, um ajuda o outro né. De mãos dadas para o bem de todos que vivem da agricultura e precisam dela para o sustento da família. Mas é uma via de mão dupla, que vai e que vem, entendeu? (Entrevistado 06, 43 anos, agricultor).

Os trechos apresentados acima trazem claramente a importância da dimensão social nas representações dos agricultores sobre sua organização produtiva, já que falam da realidade do próprio entrevistado, ou seja, do seu vínculo com a agricultura e o papel importante da organização para o desenvolvimento da agricultura familiar na região. Neste sentido, perceber a organização produtiva dos agricultores permite mapear suas relações sociais, quer seja de união e também de responsabilidade, ou seja, esta relação é "uma via de mão dupla" como relata um dos entrevistados. Além disso, estes depoimentos se norteiam por uma economia moral e também por uma ética de subsistência, como propõe Scott (1985).

Conforme este autor, a ética da subsistência, além da estratégia produtiva, pressupõe a manutenção de regras sociais baseadas em relações de reciprocidade do camponês com parentes, amigos, vizinhos e de modo mais distanciado, com o próprio Estado. Esta ética também serve de elemento balizador das relações de trabalho do pequeno agricultor e do seu comportamento diante do contexto sociopolítico implementado, como encontrado por Silva (1998) ao analisar os constrangimentos vividos pelos agricultores em consequências da modernização da agricultura nas famílias residentes das aldeias minhotas no Norte de Portugal. Quanto às transformações percebidas pelos produtores em seu modo de vida, houve unanimidade na valoração das vantagens econômicas geradas pela organização, que refletiu significativamente na economia familiar dos produtores:

Mudou bastante, nossa! Pra você ter uma ideia, antes da gente se organizar aqui na comunidade, a gente não tinha dinheiro pra nada. Pra te falar verdade, pra comê nós tinha. Fome nunca teve, mas necessidade sim. Depois que comecei a 
reunir com outros produtores e nos organizar para saber de que forma nós podemos melhorar nossa produção, melhorou muito as coisas por aqui (Entrevistado 05,50 anos, agricultor).

Nas percepções dos agricultores entrevistados, houve um predomínio e uma frequência maior nas opiniões positivas (favoráveis) à organização social e produtiva local, que veem com otimismo a possibilidade de conciliar os interesses individuais com os coletivos. Tais representações sociais espelham, de fato, como bem ensinou Minayo (1995), categorias de pensamento pelas quais uma sociedade elabora, reelabora e expressa a sua realidade. Assim, à medida que os interesses coletivos são atingidos, uma nova realidade é gestada dentro da organização produtiva dos agricultores, legitimando suas práticas e decisões sobre o que produzir e de que forma produzir, considerando o campo como um espaço cotidiano dotado de significados e sociabilidades.

Para Goffman (1999), o espaço pode ser definido como um dos idiomas que as pessoas utilizam em momentos de interação. Dessa forma, o modo como se comportam e se apropriam de determinado espaço transmite, assim como a própria fala, o que elas querem dizer, como se sentem neste espaço, como querem que outras pessoas as vejam. Os usos que as pessoas fazem dos espaços dependem das representações construídas e compartilhadas pelos sujeitos e são manifestados através de suas atitudes e comportamentos.

Acredita-se assim que, nas relações face a face, os pequenos agricultores tornam-se conscientes dos jogos de representação que marcam seu cotidiano de vida e de trabalho, podendo atuar ou representar de acordo com as regras já existentes. Diante do exposto, os resultados deste estudo vieram confirmar a hipótese de que a organização produtiva do café da região de Araponga/MG, apreendida por meio da memória coletiva dos agricultores, apresenta-se sob o signo da resistência.

\section{CONSIDERAÇÕES FINAIS}

Este estudo mostrou que a construção de estratégias de resistência e/ou adaptação desenvolvidas pelos agricultores familiares na região estudada contribuíram para a revitalização do espaço rural, reafirmando a relevância da agricultura familiar no cenário nacional. Neste contexto, nota-se uma revalorização identitária do "ser agricultor familiar" na qual se assenta a capacidade dos agricultores em elaborar estratégias coletivas no âmbito da agricultura familiar em um processo de revitalização do rural.

Com relação à organização produtiva, as representações sociais dos pequenos agricultores foram marcadas pelas sociabilidades que estes agricultores constroem com seus vizinhos, amigos e com a comunidade, formando um projeto cooperativo de desenvolvimento local; ou seja, quanto mais cooperativos no que se refere às atividades produtivas, principalmente quanto ao cultivo do café, mais forte e coesa é sua organização. Desta forma, a unidade produtiva pode ser considerada como expressão de um conjunto de representações de seus donos e daqueles que nela trabalham, através de um olhar no qual se nota uma espécie de sentimento de orgulho parecido com o de um artista que admira sua tela após a última pincelada.

Por fim, destacamos que o ponto de partida para o sucesso da organização produtiva destes agricultores pode ser justamente a percepção de sua própria identidade de agricultor e seu significado para a dinâmica da organização. Além disso, o espaço em que se inscreve o trabalho destes agricultores é significativo 
para estes sujeitos, demarcando as estratégias de atuação e também as relações sociais que são estabelecidas dentro desta organização.

\section{REFERÊNCIAS}

BARDIN, L. Análise de conteúdo. Lisboa: Edições 70, 1994.

BUAINAIN, A. M.; ALVES, E.; SILVEIRA, J. M.; NAVARRO, Z. (Org). O mundo rural no Brasil do século 21: a formação de um novo padrão agrário e agrícola. Brasília: Embrapa, 2014, p. 1.182.

CANDAU, J. Memória e identidade. São Paulo: Editora Contexto, 2011.

CTA - CENTRO DE TECNOLOGIAS ALTERNATIVAS DA ZONA DA MATA. Sistemas de Produção Agroecológicos. Revista 15 anos CTA, 2002.

CORRÊA, W. K.; GERARDI, L. H. O. A produção familiar e os desafios do mercado. Revista de Ciências Humanas, v. 1, n. 31, p. 109-131, 2002.

DUBY, G. Economia rural e a vida no campo no Ocidente medieval. Lisboa: Edições 70, 1962.

DURKHEIM, Émile. Sociologia e Ciências sociais. Trad. Inês D. Ferreira. São Paulo, DIFEL, 1975.

FERREIRA, A. D. D.; BRANDENBURG, A.; RODRIGUES, A. S.; SANTOS, E. B.; PINHEIRO, G.; SILVA, O. H. Resistência e empoderamento no mundo rural. Revista Estudos, Sociedade e Agricultura, Rio de Janeiro, v. 15, n. 1, p. 123-159, 2007.

GOFFMAN, E. A representação do eu na vida cotidiana. 8ํㅡ. Ed. Petrópolis: Editora Vozes, 1999.

GONZALEZ R. E. Manual sobre participação e organização para a gestão local. Cali: Foro Nacional por Colômbia, 1995.

INSTITUTO BRASILEIRO DE GEOGRAFIA E ESTATÍSTICA (IBGE). Censo demográfico de Araponga, 2010. Araponga, Minas Gerais, 2010. Disponível em: http://cidades.ibge.gov.br/xtras/perfil.php?lang=\&codmun=310370. Acesso em: Jun. de 2014.

INSTITUTO DE GEOCIÊNCIAS APLICADAS (IGA). Mapa do Estado de Minas Gerais e suas mesorregiões, 2012.

JODELET, D. Representações sociais: um domínio em Expansão. In: As representações sociais. Rio de Janeiro: UERJ, 2001.

LIMA, T. C. S.; MIOTO, R. C. T. Procedimentos metodológicos na construção do conhecimento científico: a pesquisa bibliográfica. Revista. Katálysis, v. 10 n. esp., p. 37-45, 2007.

LONG, N.; PLOEG, J. P. Heterogeneidade, ator e estrutura: para a reconstituição do conceito de estrutura. In: SCHNEIDER; S.; GAZOLLA, M. (Orgs.). Os atores do 
Desenvolvimento Rural: perspectivas teóricas e práticas sociais. Porto Alegre: Editora da UFRGS, 2011.

MINAYO, M. C. S. Pesquisa social. Petrópolis: Vozes, 2004.

NINO, L. B.; ANJOS, F. S. Usos da propriedade rural e a nova legislação ambiental no município de Pelotas, RS: uma conciliação viável? Extensão Rural, Santa Maria, v. 22, n. 03, p. 09-28, jul./set., 2015. Disponível em:

$<$ https://periodicos.ufsm.br/extensaorural/article/view/9015>. Acesso em 26 nov. 2016.

POLANYI, K. A grande transformação. Rio de Janeiro: Campus, 2000.

QUINTERO, M. C. La naturaleza de las representaciones sociales. Revista

Latinoamericana de Ciencias Sociales, Niñez y Juventude, v. 6, n. 1, p. 55-80, 2008.

RAMBAUD, P. Société rurale et urbanisation. Paris: Editions Du Seuil, 1969.

SCHNEIDER, S. Agricultura familiar e desenvolvimento rural endógeno: elementos teóricos e um estudo de caso. In: FROEHLICH, J.M.; VIVIEN DIESEL. (Org.). Desenvolvimento Rural - Tendências e debates contemporâneos. Ijuí: Editora Unijuí, 2006.

SCOTT, J. Weapons of the weak: everyday forms of peasant resistance. Yale University Press: New Haven and London, 1985.

Los dominados y el arte de la resistência. México: Ediciones Era, 2002.

SILVA, M. C. Resistir e adaptar-se: constrangimento e estratégias camponesas no Noroeste de Portugal. Porto: Edições Afrontamento, 1998.

TEDESCO, João Carlos. Terra, trabalho e família: racionalidade produtiva e ethos camponês. Passo Fundo: Ed. Universidade de Passo Fundo, 1999.

THOMPSON, E. P. Costumes em comum - Estudos sobre cultura popular tradicional. São Paulo: Companhia das Letras, 1998.

TRIVIÑOS, A. N. S. Introdução à pesquisa em ciências sociais. São Paulo: Atlas, 1995.

WANDERLEY, M. N. B. Raízes históricas do campesinato brasileiro. In: TEDESCO, J. C. (org.). Agricultura familiar: realidades e perspectivas. 3. ed. Passo Fundo: Ed. Universidade de Passo Fundo, 2001. 